\title{
A Study of a New Teaching Mode of Graphic Advertising Design
}

\author{
Yinglong Cai ${ }^{1, a}$ \\ ${ }^{1}$ Journal of jiangxi Polytechnic College, China \\ a email:
}

Keywords: Advertising Design, Graphic Design, Teaching Mode, Innovation

\begin{abstract}
Nowadays, many colleges and universities in China have set up the major of advertising design, but there are many deficiencies in the traditional teaching mode to improve students' learning enthusiasm, cultivate students' innovative spirit, practical ability and teamwork in the teaching of advertising design. Based on the author's work experience, this paper first analyzed the main problems existing in the current teaching mode of advertising design in China, and then put forward a new teaching mode based on the network background, in order to cultivate the innovative and practical ability of advertising design talents through teaching reform.
\end{abstract}

\section{Introduction}

With the development of our country's economy, the advertising industry is developing rapidly, so the demand for advertising design talents with innovative ability and practical ability is increased. Advertising design education is facing new opportunities and challenges in the new knowledge economy, so in the face of the globalization of the market, the future advertising designers not only need a profound cultural heritage, but also need to have the ability to international vision to meet the new challenges. With the popularization of information technology, the Internet has become an indispensable part of our life. In the field of advertising education, the application of network resources platform should become an integral part of learning. At present, most of the teaching mode and learning method of Graphic Advertisement Design course are old and single, so teachers should change the old teaching mode of traditional classroom teaching by the application of network information and other shared resources to support and assist learning.

\section{The Main Problems Existing in the Current Teaching Mode of Graphic Advertisement Design in China}

The major teaching content is out of line with social practice. In the social development of our country, advertising design industry is closely related to the market economy, but now many colleges and universities in our country can not adapt to the needs of social development. Knowledge acquired at school is out of touch with social needs, so many university graduates can not adapt to the company's work after entering the job, but also to spend time to learn major knowledge again, and the reason is that there are a lot of design courses in the teaching of advertising design, but the teaching model is still fixed in the class as the unit, no consideration was given to the design of the market demand, so that the completion of the work was not recognized in the community.

The skill class is single. School courses are too single and old-fashioned, with the development of the design industry, the curriculum should be gradually specialized. For example, in the enterprise image VI Design Course Teaching, through the teacher's course content explaining to 
enjoy some of the outstanding VI works of large enterprises. The way the students finish their homework is to imitate the style of the big company, often apply existing templates in the application system, ignore the nature of the industry. For example, in the design of the link, the students apply the stereotype guide template which has not adapted to the new design requirements. It is difficult to solve this problem by relying on the existing professional teaching system. Only by exploring the new teaching system, according to the requirements of the relevant design content, can we make the students flexibly complete the design tasks.

The teachers' teaching enthusiasm is not high and the students weariness is serious. In the advertising design teaching, students' weariness is a common phenomenon. In teaching management, although the teacher arranged a lot of homework and classroom discipline, the real effect is limited. This is not necessarily the discipline of the students, many feel idle in the classroom, trying to get the time to think about their own things. Teaching content aging, teaching methods and other issues have been formed in the course of the learning atmosphere is not an important factor.

\section{Design of the teaching mode of Graphic Advertisement Design Course based on the Network Background}

After many years of efforts to explore the teaching method, the new graphic advertisement design course is as the figure 1.

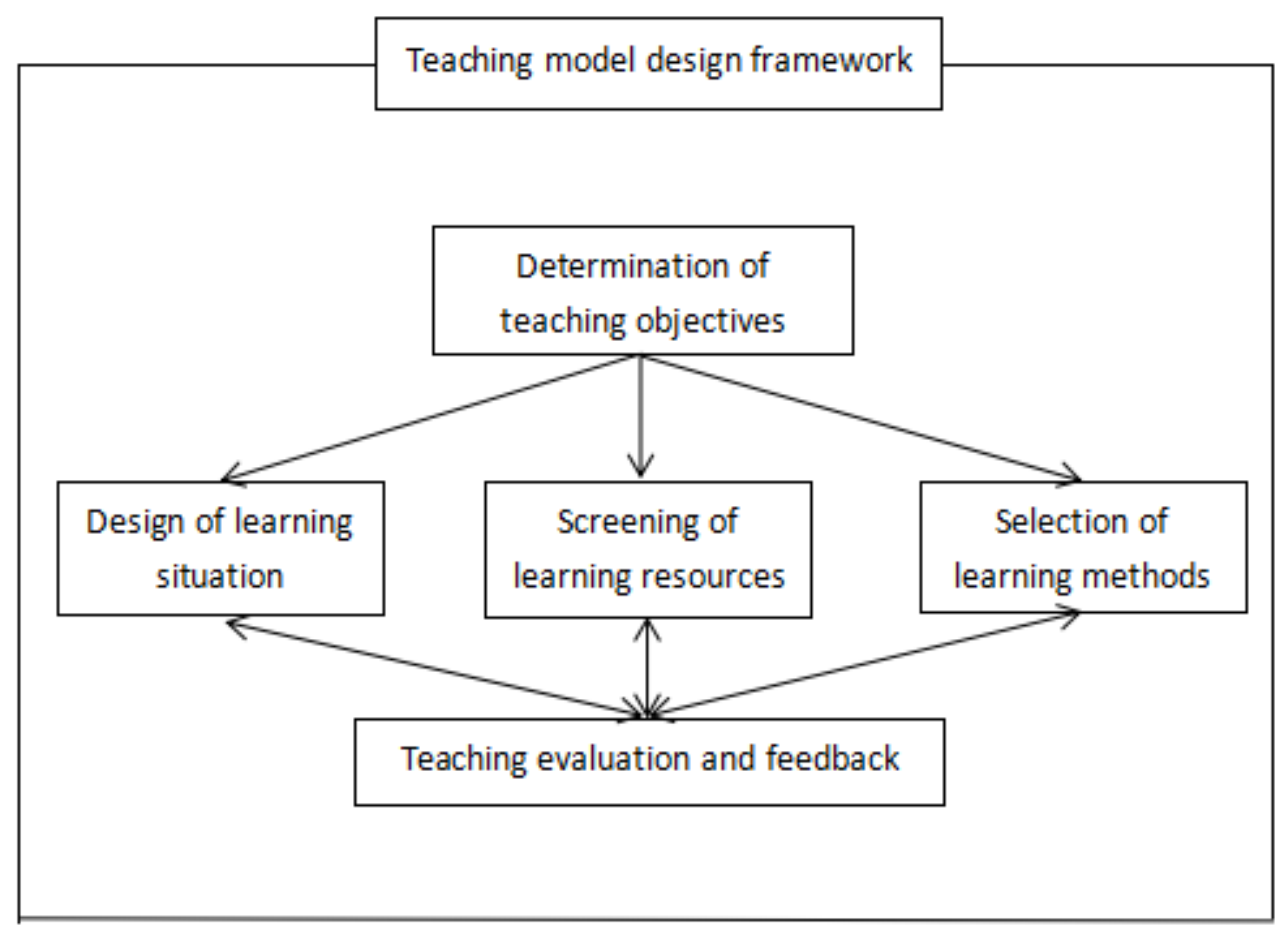

Fig.1 teaching model design framework

Determination of teaching objectives. Teaching goals should achieve the uniform of mastering the knowledge and improving the professional quality. The learning target of graphic advertisement design can be divided into 3 levels: (1) Knowledge goal enables students to have the basic theoretical knowledge, procedures and methods of advertising design, grasp the characteristics and limitations of different advertising media, understand the way of advertising communication and production and implementation, use the basic principles and methods of visual communication for advertising graphic design and rendering. (2) Ability goal enables students to be able to use the basic elements of advertising design, procedures and methods to design and produce a typical advertising products through this course kills training. (3) Quality goal enables students to improve 
their observation ability, comprehensive analysis ability, multi angle thinking ability, design ability, to cultivate students' self learning ability and teamwork spirit.

Design of learning situation. Through visits to the advertising industry, business discussion, questionnaire, etc. to follow the basic rules of advertising professional ability training, taking the typical work tasks and enterprise projects as a platform, according to the work flow of print advertisement design, taking project driven as the main line to establish a working system as a curriculum framework. Taking work as a basis, from single to comprehensive, to set the poster design, corporate brochure design, advertisement design and other projects, according to the project design of learning situation. Each item is divided into a number of learning sub situations.

Screening of learning resources. Learning based on the network context must have network environment, and the minimum requirement is that students should have a computer, and be able to surf the Internet. Speed can not be too slow to reach the normal, otherwise it will affect the students' learning mood. Advertising network resources are broadly divided into the following: (1) Material and template resource. This type of website is mainly to provide the design of the material to be used, graphic images, a variety of excellent advertising works. (2) The design course resources: This kind of website is designed to provide a variety of theoretical and practical knowledge, especially computer design software tutorials and learning methods. (3) The design of enterprise resources: This kind of website is the website of all kinds design company. (4) The design of industry resources: This kind of website is mainly a variety of excellent works of advertising, information, recruitment, professional theory, hot analysis, industry trends and so on. (5) The task of design resources: This kind of website is mainly dedicated to the purpose of the transaction, and design trading service platform to provide work tasks. As intermediary, this kind of service platform will take the enterprises or individuals with design needs as buyers, and publish the buyer demand task information to invite tenders in the way of offering a reward. Finally the buyers choose the best work in numerous works. The representative website are www.zbj.com and www.toidea.com.

Selection of learning methods. The mode of education and training should be diversified, and the development of advertising education model can not be too simplistic, too single, otherwise it will cause that the talent can not be developed for the market, and the other side will cause the school major atrophy. Teachers' multimedia teaching, students' market research and group discussion should be organically bounded. Teachers should choose appropriate teaching methods according to the actual situation, for example, in the learning situation of "advertising design industry and professional cognition", it can use multimedia teaching, student market research and other methods. In the creative phase of the project, it can use group discussion, brainstorming and so on. Students also need to improve their ability through network resources.

\section{Summary and Recommendations}

Through the research of the teaching mode of Graphic Advertising Design course, teachers should cultivate students to have a correct attitude towards the use of network resources. The learning attitude is the tendency of the students' understanding and evaluation of the learning, the emotional experience and the behavior. Learning attitude not only directly affects the efficiency of learning, but also determines the way of learning. Network resources are very powerful, and students may inevitably be confused in the initial contact and the network information.can not be identified. Especially in the face of an unusually rich material and template resources on the network, some students were wild with joy, think that they do not have their own design works because it can be used directly. Teachers must guide students to distinguish between plagiarism and draw lessons from the difference, so that students correct attitude towards learning.

For beginners, the use of network resources learning model can not completely replace the teacher's classroom teaching. Because there is no basis for beginners, they need to learn step by step 
according to the teacher's classroom teaching, and the learning model of network resources is only a supplement to the classroom teaching. After a certain professional basis, students can take advantage of their own situation to use the network resources to learn, broaden the learning area.

In the course of teaching, the task selection in design task website must be grasped by the teacher. Tasks in the designing task resources website are various, because lack of experience, students often can not grasp the timing and difficulty of project selection, so they can not achieve good results. In the teaching of Graphic Advertising Design, teachers should choose appropriate, typical tasks to guide students to complete the requirements of the teaching objectives. Today's society is in the information age, so the teachers in colleges and universities should keep up with the pace of the times, update the concept of education, use the modern information tools to enrich themselves, and actively explore more effective learning model.

\section{Acknowledgment}

Fund project: Art science planning project of Jiangxi Province(YG2015189, YG2014255);

Research project of Humanities and Social Sciences in Universities of Jiangxi Province, 2015(TQ1516);

\section{References}

[1] Tang Zhaohui. Discussion on the teaching mode of plane advertisement design course [J]. Decoration, 2008,01:134-135.

[2] Kang Yu. Plane advertisement design course project teaching exploration [J]. China Adult Education, 2011,12:140-142.

[3] Li Peng. On the teaching reform of plane advertisement design [J]. Education and Careers, 2013,35:154-155.

[4] Li Aiping, Li Xiangchen, Shao Lin. An analysis of the innovation of plane advertisement design course in the mode of combination of work and study in Higher Vocational Colleges [J]. Education and Careers, 2013,27:148-149.

[5] Sun Ming. Graphic advertising design class teaching positioning [J]. Mei Yuan, 2002,03:22-25. 